\title{
Efektivitas Booklet Nata Labu Air bagi Petani untuk Meningkatkan Keterampilan
}

\author{
Rina Kristina Maria ${ }^{1}$, Utami Sri Hastuti ${ }^{1}$, Suhadi ${ }^{1}$ \\ ${ }^{1}$ Pendidikan Biologi-Universitas Negeri Malang
}

\section{INFO ARTIKEL}

\section{Riwayat Artikel:}

Diterima: 14-02-2019

Disetujui: 15-04-2020

\section{Kata kunci:}

gourd farmer;

booklet;

nata from gourd;

petani labu air;

booklet;

nata dari labu air

\section{Alamat Korespondensi:}

\section{Rina Kristina Maria}

Pendidikan Biologi

Universitas Negeri Malang

Jalan Semarang 5 Malang

E-mail: rinamaria01@gmail.com

Pendidikan nonformal merupakan salah satu jenis pendidikan yang diakui di Indonesia selain pendidikan formal dan informal. Kegiatan pendidikan nonformal dilakukan secara terstruktur, berjenjang, berada di luar jalur pendidikan nonformal (UU Sisdiknas No.20 Tahun 2003, n.d.), serta dilakukan di luar kelas(Tudor, 2016). Tujuan pendidikan nonformal yaitu untuk melatih keterampilan bagi masyarakat putus sekolah(Kedrayate, 2012), meningkatkan kesejahteraan masyarakat sehingga mampu mengurangi angka kemiskinan (Akpama, Asor, Esang, \& Esang, 2011) serta sebagai pengganti dan/atau pelengkap pendidikan formal(Bacquelaine \& Raymaekers, 1991;Shephard, 2014).

Hasil analisis kebutuhan menunjukkan bahwa petani labu air hanya menjual buah labu air dalam kondisi segar dan belum pernah mengenal cara mengolah makanan berbahan dasar labu air supaya memiliki nilai jual yang tinggi (100\%). Latar belakang pendidikan formal yang rendah, yaitu tidak lulus SMP (80\%), tidak menyurutkan minat petani untuk belajar cara mengolah buah labu air menjadi nata $(90 \%)$. Petani menyatakan bahwa dalam kegiatan pembelajaran tersebut diperlukan booklet untuk memudahkan proses penyuluhan $(85 \%)$.

Penyuluhan merupakan kegiatan penyebarluasan informasi (Padmo, 2000) dan termasuk dalam sistem pendidikan nonformal yang ditujukan bagi petani beserta keluarganya (Wiriatmaja, 1990). Penyuluhan bermanfaat untuk meningkatkan pengetahuan, sikap dan keterampilan petani (Hamalik, 1990). Kegiatan penyuluhan memerlukan media pembelajaran untuk membantu memperlancar kegiatan pembelajaran.Booklet termasuk salah satu jenis media pembelajaran yang berfungsi untuk mendukung penyampaian informasi dengan sistematika yang sederhana, jelas, dan obyektif(Varela, Rosa, Radünz, Salum, \& Souza, 2017). Booklet memiliki beberapa keunggulan, yaitu berukuran kecil, ditulis secara sistematis dan praktis, serta dilengkapi dengan gambar untuk mempermudah penjelasan (Sulaiman, 1998) sehingga masyarakat bisa melakukan langkahlangkah seperti yang sudah tergambar pada booklet (Effendi, 2009). Berdasarkan uraian tersebut, maka diharapkan melalui booklet penyuluhan tentang "Nata dari Labu Air" para petani memperoleh keterampilan dalam hal membuat dan mengolah nata dari labu air sehingga dapat diaplikasikan dalam kegiatan kewirausahaan. 
Keterampilan merupakan kemampuan untuk menyelesaikan tugas dengan baik berdasarkan pengetahuan teoritis yang telah dimiliki (Sudarto, 2016). Keterampilan dapat ditingkatkan apabila selama proses pembelajaran menggunakan media belajar yang tepat (Prasetya, 2012) dan dengan memberikan pengalaman langsung berupa praktik (Muliadi \& Arjun, 2016). Penelitian ini bertujuan untuk menguji efektivitas booklet penyuluhan bagi petani labu air yang telah tersusun dalam meningkatkan keterampilan membuat nata dari labu air.

\section{METODE}

Penelitian ini merupakan penelitian pengembangan berbasis penelitian eksperimen dengan menggunakan model (Hannafin \& Peck, 1998) yang terdiri dari tiga tahap, yaitu tahap analisis kebutuhan, tahap rancangan, serta tahap pengembangan dan implementasi. Ketiga tahap tersebut selalu di evaluasi dan direvisi sebelum melangkah ke tahap berikutnya.

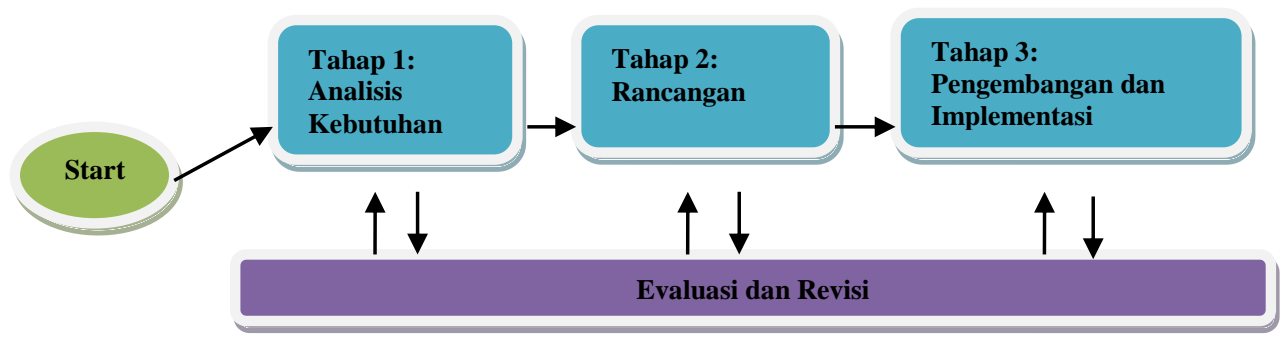

Gambar 1. Model Pengembangan Hannafin \& Peck (1988)

Penyusunan booklet didasarkan pada hasil analisis kebutuhan yang dilakukan dengan cara menyebarkan angket kepada petani labu air serta sebagian hasil penelitian eksperimen. Berdasarkan hasil analisis kebutuhan kepada para petani labu air diperoleh informasi bahwa (1) para petani buah belum mengetahui bahwa buah labu air dapat dimanfaatkan sebagai bahan dasar pembuatan nata, (2) para petani buah juga belum mengetahui langkah kerja pembuatan nata labu air, dan (3) teknik pengemasan nata labu air. Selanjutnya, materi penyuluhan disusun berdasarkan hasil analisis kebutuhan dan hasil penelitian Eksperimen yang dilakukan oleh penulis, terutama pada langkah kerja dan teknik pengemasan nata labu air.

Rancangan booklet kemudian divalidasi oleh ahli Mikrobiologi dan ahli Media Pembelajaran, kemudian dilakukan uji keterbacaan produk kepada para petani labu air. Booklet yang tersusun dicetak menggunakan art paper ukuran A5, memakai huruf tipe Arial. Isi booklet terdiri atas empat BAB sebagaimana dicantumkan pada tabel 1.

Tabel 1. Penjabaran Isi Booklet

\begin{tabular}{|c|c|c|}
\hline No. & Isi & Penjabaran \\
\hline 1. & Judul & Identitas Booklet \\
\hline 2. & Halaman Awal & Kata Pengantar dan Daftar Isi \\
\hline 3. & BAB I & Mengenal Nata de Coco dan Manfaatnya Bagi Kesehatan \\
\hline \multirow[t]{3}{*}{4.} & BAB II & 1. Mengenal Labu Air \\
\hline & & 2. Karakteristik dan Kandungan Nutrisi Buah Labu Air \\
\hline & & 3. Prospek Pemanfaatan Buah Labu Air sebagai Bahan Dasar Pembuatan Nata \\
\hline \multirow[t]{4}{*}{5.} & BAB III & 1. Alat yang Diperlukan untuk Pembuatan Nata Labu Air \\
\hline & & 2. Bahan yang Diperlukan untuk Pembuatan Nata Labu Air \\
\hline & & 3. Langkah Kerja Pembuatan Nata Labu Air \\
\hline & & 4. Teknik Pengolahan Nata Labu Air \\
\hline \multirow[t]{3}{*}{6.} & BAB IV & 1. Teknik Pengemasan Nata Labu Air \\
\hline & & 2. Analisis Usaha Pembuatan Nata Labu Air \\
\hline & & 3. Strategi Pemasaran Nata Labu Air \\
\hline \multirow[t]{2}{*}{7.} & Penutup & 1. Daftar Pustaka \\
\hline & & 2. Biografi Penulis \\
\hline
\end{tabular}


Materi booklet divalidasi oleh validator ahli Mikrobiologi dan validasi media pembelajaran oleh validator ahli media pembelajaran. Uji keterbacaan dilakukan oleh 10 orang petani labu air. Data yang didapat berupa data kuantitatif dan kualitatif. Data kualitatif berupa saran dan komentar untuk perbaikan booklet. Data kuantitatif berupa skor dan dianalisis menggunakan rumus berikut.

$$
P=\frac{x}{x i} \times 100 \%
$$

$\begin{array}{lll}\text { Keterangan: } \quad & \mathrm{P} & \text { Persentase Validitas } \\ \mathrm{x} & = & \text { Jumlah skor jawaban } \\ \mathrm{xi} & = & \text { Jumlah skor ideal } \\ 100 \% & = & \text { Konstanta }\end{array}$

Kriteria validitas, keterbacaan, dan keefektifan disajikan pada tabel 2 berikut.

Tabel 2. Kriteria Validitas, Keterbacaan, dan Keefektifan Booklet

\begin{tabular}{ll}
\hline Persentase & Kriteria \\
\hline $85,01 \%-100 \%$ & Sangat valid/sangat layak/sangat efektif \\
$70,01 \%-85 \%$ & Cukup valid/cukup layak/cukup efektif \\
$50,01 \%-70 \%$ & Kurang valid/kurang layak/kurang efektif \\
$01,00 \%-50 \%$ & Tidak valid/tidak layak/tidak efektif \\
\hline
\end{tabular}

Sumber: Modifikasi dari Akbar (2013)

\section{HASIL}

Ringkasan hasil validasi dari ahli materi dan ahli media disajikan pada tabel 3. Berdasarkan hasil validasi oleh ahli materi dan ahli media pembelajaran tersebut, dapat diketahui bahwa booklet yang telah tersusun sudah berkualitas sangat valid, sehingga dapat digunakan dengan revisi sebagian kecil sesuai dengan saran dari validator. Selanjutnya dilakukan uji keterbacaan kepada para petani.Hasil uji keterbacaan disajikan pada tabel 4. Hasil uji keterbacaan menunjukkan bahwa booklet sangat valid untuk digunakan pada kegiatan penyuluhan pembuatan nata. Booklet penyuluhan digunakan untuk mengukur keterampilan petani selama proses pembuatan, pengolahan, dan pengemasan nata labu air. Ringkasan hasil keterampilan yang diukur disajikan pada Tabel 5.

Tabel 3. Ringkasan Hasil Validasi Ahli Materi dan Ahli Media

\begin{tabular}{cccccc}
\hline \multirow{2}{*}{ No. } & \multicolumn{2}{c}{ Aspek Penilaian } & \multicolumn{2}{c}{ Ahli Materi } & \multicolumn{2}{c}{ Ahli Media } \\
\cline { 3 - 6 } & & Persentase & Kategori & Persentase & Kategori \\
\hline 1. & Desain Booklet Penyuluhan & 100 & Sangat Valid & 100 & Sangat Valid \\
2. & Bab I. Pendahuluan & 96,88 & Sangat Valid & 100 & Sangat Valid \\
3. & Bab II. Labu Air sebagai Bahan Pembuatan Nata & 87,50 & Sangat Valid & 96,43 & Sangat Valid \\
4. & Bab III. Pembuatan Nata Labu Air & 85 & Cukup Valid & 100 & Sangat Valid \\
5. & Bab IV. Pengemasan dan Pemasaran & 88,89 & Sangat Valid & 100 & Sangat Valid \\
\multicolumn{2}{l}{ Rerata dan Kategori Hasil } & 91,65 & Sangat Valid & 99,29 & Sangat Valid \\
\hline
\end{tabular}

Tabel 4. Ringkasan Hasil Uji Keterbacaan

\begin{tabular}{llll}
\hline No. & Aspek Penilaian & Persentase & Kategori \\
\hline 1. & Desain Booklet Penyuluhan & 99,50 & Sangat Valid \\
2. $\quad$ Isi Booklet Penyuluhan & 95,83 & Sangat Valid \\
Rerata dan Kategori Hasil & 97,68 & Sangat Valid \\
\hline
\end{tabular}


Tabel 5. Ringkasan Hasil Penilaian Keterampilan Para Petani Buah Labu Air

\begin{tabular}{llll}
\hline No. & Keterampilan yang Dinilai & Persentase & Kategori \\
\hline 1. & Mengenal alat dan bahan dalam membuat nata & 93,75 & Sangat Efektif \\
2. & Membuat nata sesuai langkah kerja pada booklet & 93,75 & Sangat Efektif \\
3. & Menghasilkan nata yang berkualitas baik & 90 & Sangat Efektif \\
4. & Mengolah nata sesuai petunjuk pada booklet & 91,25 & Sangat Efektif \\
5. & Mengemas nata yang siap dipasarkan & 91,25 & Sangat Efektif \\
Rerata dan Kategori Hasil & 92 & Sangat Efektif \\
\hline
\end{tabular}

Tabel 5 menunjukkan bahwa booklet sangat efektif digunakan untuk melatih keterampilan petani dalam membuat, mengolah, dan mengemas nata labu air.

\section{PEMBAHASAN}

Era modern menuntut setiap individu untuk memiliki kompetensi mengetahui bagaimana melakukan sesuatu (to know how to do) dan bagaimana cara bertindak (how to act). Kompetensi tersebut termasuk kedalam keterampilan hidup (life skill) yang harus dimiliki oleh setiap individu agar bisa menjalani proses kehidupan dengan baik, dan bisa diperoleh melalui pendidikan nonformal (Ilahi, 2012). Pendidikan nonformal berfungsi untuk mengembangkan potensi peserta didik dalam hal penguasaan pengetahuan dan keterampilan serta pengembangan sikap dan kepribadian. Pendidikan nonformal tidak lepas dari pemahaman pembelajaran sepanjang hayat yang berguna untuk meningkatkan kemampuan pribadi maupun komunitasnya (Norqvist, 2017; Latchem, 2014). Salah satu bentuk pelaksanaan pendidikan nonformal yaitu kegiatan penyuluhan.

Kegiatan penyuluhan pembuatan nata labu air bertujuan untuk memberikan keterampilan kepada petani labu air dalam mengolah buah labu air menjadi nata. Labu air yang telah diolah menjadi nata memiliki nilai jual yang lebih tinggi bila dibandingkan dengan nilai jual buah labu air segar. Kegiatan penyuluhan dapat meningkatkan kemampuan petani dalam membuat nata labu air, sehingga diharapkan dapat mengubah dan meningkatkan kesejahteraan petani labu air dalam jangka pendek sampai jangka panjang (Karsidi, 2001).

Kegiatan penyuluhan dalam pelaksanaannya membutuhkan media pembelajaran. Media pembelajaran yang tepat disesuaikan dengan kebutuhan dan latar belakang petani. Booklet dipilih sebagai media penyuluhan karena memiliki keunggulan, yaitu (1) berukuran kecil, (2) dilengkapi gambar sesuai aslinya, (3) ditulis secara ringkas dan sistematis, (4) dicetak pada kertas jenis artpaper (Sulaiman, 1998); (Kemm \& Close, 1995); (Ewles \& Simnett, 1994). Booklet yang dikembangkan disesuaikan dengan latar belakang pendidikan petani serta memperhatikan fasilitas alat dan bahan yang sudah umum dikenal oleh petani.Booklet yang dihasilkan mudah dibawa dan dibaca dimana saja, mudah dipahami, dan tidak mudah rusak ketika terkena air.Booklet yang dikembangkan merupakan hasil dari analisis kebutuhan yang telah dilakukan oleh peneliti serta didasarkan pada sebagian hasil penelitian eksperimen, terutama pada bagian langkah kerja pembuatan dan pengemasan nata dari labu air.

Materi booklet terdiri atas empat bab, yaitu Bab I. Pendahuluan, Bab II. Labu Air sebagai Bahan Pembuatan Nata, Bab III. Pembuatan Nata Labu Air, dan Bab IV. Pengemasan dan Pemasaran. Setiap bab dilengkapi dengan gambar yang menarik dan jelas sesuai dengan keadaan sebenarnya. Gambar bertujuan untuk memudahkan petani dalam memahami informasi penting yang terdapat pada booklet. Informasi tersebut berkaitan dengan nata dan manfaatnya bagi kesehatan, mengenal labu air serta nutrisi yang terdapat didalamnya, prospek buah labu air sebagai bahan pembuatan nata, alat dan bahan yang digunakan untuk membuat nata, serta analisis usaha pembuatan nata labu air. Gambar dapat memudahkan petani dalam mengikuti instruksi yang tertulis pada booklet. Instruksi berkaitan tentang Langkah Kerja Membuat Nata, Teknik Mengolah dan Mengemas Nata, serta Strategi Pemasaran Nata Labu Air. Booklet yang telah disusun selanjutnya divalidasi oleh ahli materi dan ahli media. Selanjutnya dilakukan uji keterbacaan kepada 10 orang petani sebagai responden.

Hasil validasi dari ahli materi dan ahli media pembelajaran menunjukkan bahwa booklet yang telah disusun masuk kedalam kriteria sangat valid. Hasil uji keterbacaan juga menunjukkan bahwa booklet sudah sangat valid. Booklet dengan kriteria sangat valid memiliki arti bahwa booklet dapat digunakan sebagai media kegiatan penyuluhan pembuatan nata labu air dengan terlebih dahulu dilakukan revisi pada sebagian kecil produk. Booklet yang sudah direvisi sesuai saran dan komentar validator kemudian digunakan sebagai media pembelajaran dalam kegiatan penyuluhan.Kegiatan penyuluhan bertujuan memberikan keterampilan membuat makanan olahan berbahan dasar buah labu air.Keterampilan petani dalam membuat, mengolah, dan mengemas nata diamati dan dinilai.Keefektifan booklet sebagai media penyuluhan diperoleh berdasarkan hasil penilaian keterampilan petani.Hasil penilaian keterampilan petani menunjukkan bahwa booklet sangat efektif digunakan dalam penyuluhan yang bertujuan untuk meningkatkan keterampilan petani dalam membuat, mengolah, dan mengemas nata labu air. 


\section{SIMPULAN}

Booklet nata labu air yang digunakan sebagai media penyuluhan telah tersusun dan memiliki kriteria sangat valid dan sangat efektif untuk digunakan dalam penyuluhan yang bertujuan untuk meningkatkan keterampilan petani dalam membuat, mengolah, dan mengemas nata labu air. Para peneliti dapat mengembangkan booklet pembuatan nata dari buah selain labu air yang berbasis pada penelitian eksperimen agar bersifat lebih kontekstual dan dapat membantu meningkatkan keterampilan para petani buah.

\section{DAFTAR RUJUKAN}

Akpama, S. I., Asor, L. J., Esang, O. U., \& Esang, W. O. (2011). Non-formal Education Programmes and Poverty Reduction among Young Adults in Southern Senatorial District Cross River State, Nigeria. Journal of Educational and Developmental Psychology, 1(1), 154-161. https://doi.org/10.5539/jedp.v1n1p154

Bacquelaine, M., \& Raymaekers, E. (1991). Non-Formal Education in Developing Countries. International Journal of Educational Management, 5(5). https://doi.org/10.1108/09513549110134770

Hannafin, M. J., \& Peck, K. L. (1998). The Design Development and Evaluation of Instructional Software. New York: Macmillan Publishing Company.

Ilahi, M. T. (2012). Pembelajaran Discovery Strategy dan Mental Vocational Skill: Tutorial Inspiratif bagi Para Pembelajar. Yogyakarta: DIVA Press.

Karsidi, R. (2001). Paradigma Baru Penyuluhan Pembangunan dalam Pemberdayaan Masyarakat. Mediator: Jurnal Komunikasi, 2(1), 115-125.

Kedrayate, A. (2012). Non-Formal Education : Is It Relevant or Obsolete? International Journal of Business, Humanities and Technology, 2(4), 11-15.

Kemm, J., \& Close, A. (1995). Health Promotion: Theory and Practice (eds). London: McMillan.

Latchem, C. (2014). Informal Learning and Non-Formal Education for Development Maximising Human Potential. Journal of

Learning for Dvelopment, (2).

Muliadi, A., \& Arjun, M. A. (2016). IbM Pembinaan Petani Kopra Berbasis Entrepreneurship. Lumbung Inovasi: Jurnal Pengabdian kepada Masyarakat, 1(1), 35-37.

Norqvist, L. (2017). Learning in Non-Formal Education : Is it "Youthful" for Youth in Action? International Review of Education, 63(2), 235-256. https://doi.org/10.1007/s11159-017-9631-8

Padmo, S. (2000). Media Penyuluhan Pertanian dan Komunikasi. Jakarta: Departemen Pertanian.

Prasetya, T. I. (2012). Meningkatkan Keterampilan Menyusun Instrumen Hasil Belajar Berbasis Modul Interaktif bagi GuruGuru IPA SMP N Kota Magelang. Journal of Educational Research and Evaluation, 1(2), 106-112.

Shephard, D. D. (2014). Nonformal Education for Improving Educational Outcomes for Street Children and Street Youth in Developing Countries: A Systematic Review. International Journal of Social Welfare, 23(4), 349-361.

Sudarto. (2016). Pendidikan Dalam Perspektif Islam. Al-Lubab: Jurnal Penelitian Pendidikan dan Keagamaan Islam, 2(1), $105-120$.

Sulaiman. (1998). Media Pendidikan. Jakarta: CV Rajawali.

Tudor, S. L. (2016). Formal - Non-formal - Informal In Education. Procedia - Social and Behavioral Sciences, 76, 821-826. DOI: $10.1016 / j$. sbspro.2013.04.213

Varela, A. I. S., Rosa, L. M. da, Radünz, V., Salum, N. C., \& Souza, A. I. J. de. (2017). Educational Booklet for Patients in Palliative Care and Their Families: Construction Strategies. Journal of Nursing, 11(7), 2955-2962.

Wiriatmaja, S. (1990). Pokok-Pokok Penyuluhan Pertanian. Jakarta: PT Yasa Guna. 